archives-ouvertes

\title{
Vertigo and impaired pursuit eye movements in a small medial superior temporal infarction
}

\author{
Christophe Lopez
}

\section{To cite this version:}

Christophe Lopez. Vertigo and impaired pursuit eye movements in a small medial superior temporal infarction. Journal of Neurology, Springer Verlag, 2018, 265 (11), pp.2740-2742. 10.1007/s00415-0189023-4 . hal-02121660

\section{HAL Id: hal-02121660 https://hal-amu.archives-ouvertes.fr/hal-02121660}

Submitted on 6 May 2019

HAL is a multi-disciplinary open access archive for the deposit and dissemination of scientific research documents, whether they are published or not. The documents may come from teaching and research institutions in France or abroad, or from public or private research centers.
L'archive ouverte pluridisciplinaire HAL, est destinée au dépôt et à la diffusion de documents scientifiques de niveau recherche, publiés ou non, émanant des établissements d'enseignement et de recherche français ou étrangers, des laboratoires publics ou privés. 


\title{
Vertigo and impaired pursuit eye movements in a small medial superior temporal infarction
}

\author{
Jeong-Min Kim ${ }^{1} \cdot$ Seog Kyun Mun ${ }^{2} \cdot$ II-Han Yoo ${ }^{1} \cdot$ Christophe Lopez ${ }^{3} \cdot \mathrm{Ji}^{-S o o} \mathrm{Kim}^{4} \mathbb{C}$
}

Dear Sirs,

Vertigo may occur in lesions involving the cerebral hemispheric regions such as the insular cortex, retroinsular area and temporo-parietal junction [1]. However, no study has described vertigo and impaired pursuit eye movements as the only findings of supratentorial strokes. We report isolated vertigo and impaired pursuit eye movements to the lesion side in a patient with a small infarction restricted to the deep white matter of left superior temporal gyrus. This report suggests the subcortical location of the fibers to and from the human homologue of parieto-insular vestibular cortex and medial superior temporal (MST) area in monkeys.

A 75-year-old woman reported two episodes of spontaneous vertigo with illusory self-motion lasting several minutes. She denied associated headache, diplopia, dysarthria, visual field defects or limb weakness/sensory disturbance. She had a history of left cerebellar infarction 5 years before, but without neurological sequelae and had been taking aspirin $100 \mathrm{mg}$ per day. She showed no spontaneous nystagmus, ocular misalignment, limitation of extraocular movements or head tilt, but her smooth pursuit was impaired to the left. Limb ataxia or gait imbalance was not observed. Dix-Hallpike and other positioning tests did not elicit vertigo or nystagmus. In view of the old age, previous stroke history and

Ji-Soo Kim

jisookim@snu.ac.kr

1 Department of Neurology, Chung-Ang University Hospital, Seoul, Republic of Korea

2 Department of Otorhinolaryngology, Chung-Ang University Hospital, Seoul, Republic of Korea

3 Centre National de la Recherhe Scientifique, Aix-Marseille Université, LNSC, Marseille, France

4 Department of Neurology, Dizziness Center, Clinical Neuroscience Center, Seoul National University College of Medicine, Seoul National University Bundang Hospital, 82 Gumi-ro, Bundang-gu, Seongnam 13620, Republic of Korea transient vertigo lasting several minutes led us to suspect a vascular etiology and to proceed brain imaging. Brain MRIs disclosed an acute infarction involving the deep white matter of the left superior temporal gyrus (Fig. 1a-c) and a focal stenosis of the left internal carotid artery in the cavernous portion. Video-oculography 5 days after the symptom onset documented normal saccades, but impaired smooth pursuit and absent optokinetic responses (Fig. 1d, e) during leftward stimulation. Findings of bithermal caloric tests and pure tone audiogram were normal. She was discharged with an addition of clopidogrel of $75 \mathrm{mg}$ and atorvastatin of $40 \mathrm{mg}$ per day to her previous medication and without further recurrences of the vertigo. Oculography after 8 months documented normalized smooth pursuit and optokinetic nystagmus in the horizontal plane.

The vestibular system and ocular motor system for pursuit eye movements and optokinetic nystagmus should work in close cooperation to maintain visual acuity during head motion. However, the structures relaying these systems in the cerebral hemisphere require further elucidation in human. Several hemispheric regions including the retro-insular area, parietal cortex and superior temporal gyrus have been the candidates for the human homologue of the parieto-insular vestibular cortex in nonhuman primates [2]. Smooth pursuit is controlled by a network encompassing the frontal and posterior cortical areas, which overlap or interconnect with the cortical vestibular network [3]. Various types of impaired smooth pursuit were reported in patients with injuries to the posterior parietal cortex, frontal eye field, dorsolateral prefrontal cortex, or the supplementary motor area [4]. In monkeys, neural activities related to pursuit eye movements are found in both MT and MST areas, and lesions involving either MT or MST impair ocular pursuit for the moving targets [5]. Our group previously reported a patient with ipsiversive spontaneous nystagmus and impaired smooth pursuit due to a lesion involving the parieto-temporo-occipital cortices [6]. Human studies with functional MRI disclosed that vestibular stimuli in darkness strongly activated human MST 

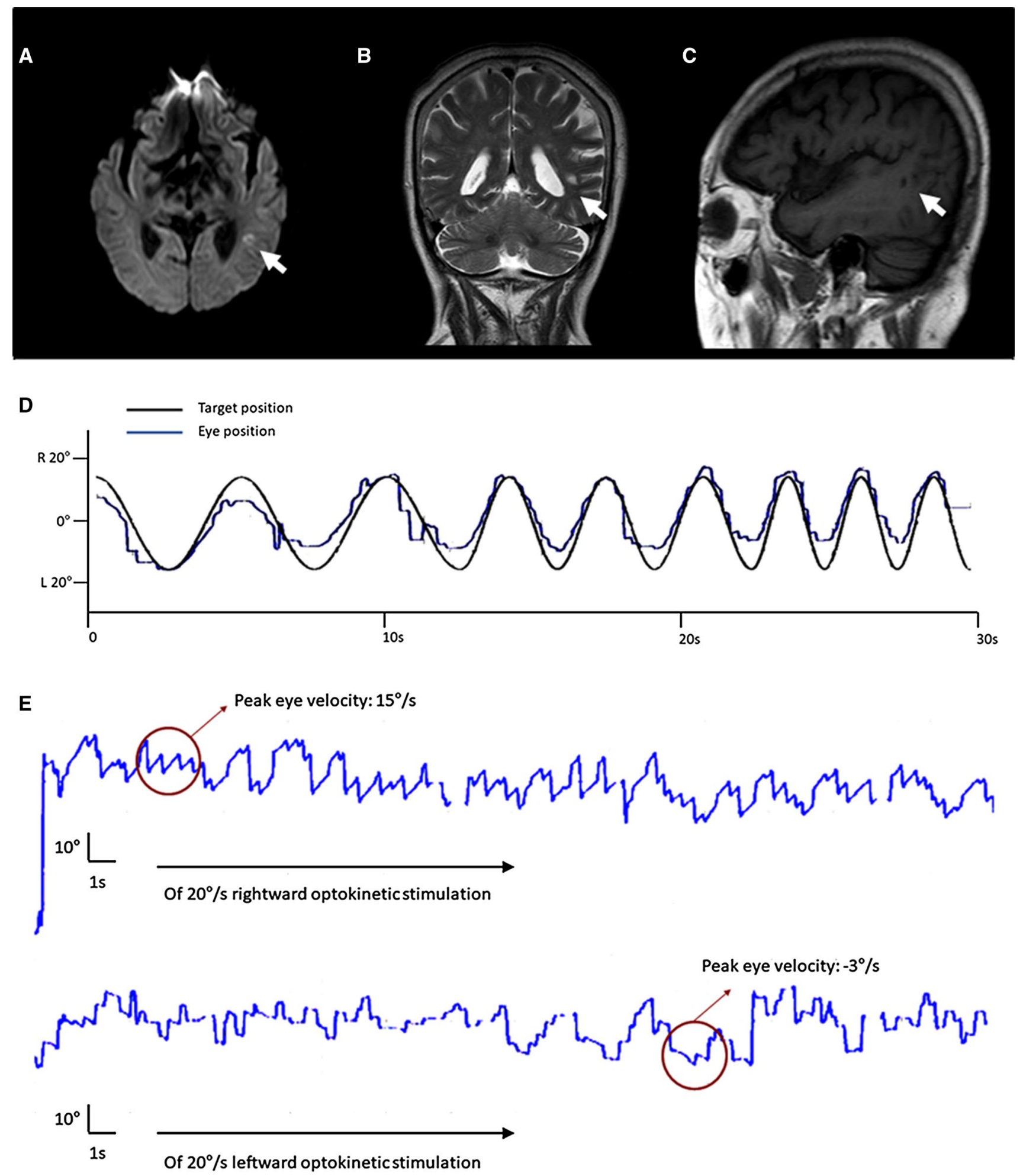

Fig. 1 Brain MRI and video-oculographic findings. An acute focal infarction (white arrow) is shown in the left medial superior temporal gyrus on axial diffusion-weighted (a), coronal T2-weighted (b) and sagittal T1-weighted MRIs (c). Video-oculography documents impaired smooth pursuit to the left (rightward gain 0.70, leftward gain 0.25 , normal range $0.70-1.00$, d) and no nystagmus generation during leftward optokinetic stimulation (e) 
and cingulate sulcus visual area, but not MT [7]. The present case supports the prior localization of human homologue of the MST area, and implicates that a small lesion involving the temporo-parietal junction could evoke both vertigo and impaired ipsilateral pursuit eye movements by disrupting the fibers to and from the parieto-insular vestibular cortex and human homologue of the MST in monkeys. The illusory self-motion experienced during the attack of vertigo also strongly supports involvement of the MST in our patient. She had only short episodes of vertigo in the presence of a documented ischemic lesion on MRIs. The small size of the lesion in the subcortical area may be a reason for these brief episodes of spontaneous vertigo. Otherwise, epileptic vertigo from the acute stroke may be an alternative explanation [8].

Acknowledgements This study was supported by Basic Science Research Program through the National Research Foundation of Korea (NRF) funded by the Ministry of Education, Science and Technology (no. NRF-2016R1D1A1B04935568).

Author contributions J-MK analyzed and interpreted data and wrote the manuscript. SKM, I-HY and CL analyzed and interpreted data and revised manuscript. J-SK designed and conceptualized the study, interpreted the data, and revised the manuscript.

\section{Compliance with ethical standards}

Conflicts of interest Jeong-Min Kim, Seog Kyun Mun, Il-Han Yoo and Christophe Lopez report no disclosure. Christophe Lopez serves as an associated editor of Frontiers in Integrative Neuroscience and guest editor of Frontiers in Neurology. Ji-Soo Kim serves as an associate editor of Frontiers in Neuro-otology and on the editorial boards of the Journal of Clinical Neurology, Frontiers in Neuro-ophthalmology, Journal of Neuro-ophthalmology, Journal of Vestibular Research, Journal of Neurology, and Medicine.

Ethical standards This study was performed in accordance with the guidelines of Institutional Review Board of Chung-Ang University Hospital (C2013110-1070) and ethical standards laid down in the 1964 Declaration of Helsinki.

\section{References}

1. von Brevern M, Süßmilch S, Zeise D (2014) Acute vertigo due to hemispheric stroke: a case report and comprehensive review of the literature. J Neurol Sci 339:153-156

2. Lopez C, Blanke O (2011) The thalamocortical vestibular system in animals and humans. Brain Res Rev 67:119-146

3. Guldin WO, Grüsser OJ (1998) Is there a vestibular cortex? Trends Neurosci 21:254-259

4. Heide W, Kurzidim K, Kömpf D (1996) Deficits of smooth pursuit eye movements after frontal and parietal lesions. Brain 119:1951-1969

5. Petit L, Haxby JV (1999) Functional anatomy of pursuit eye movements in humans as revealed by fMRI. J Neurophysiol 82:463-471

6. Choi SY, Kim Y, Oh SW, Jeong SH, Kim JS (2012) Pursuitparetic and epileptic nystagmus in MELAS. J Neuroopthalmol 32:135-138

7. Smith AT, Wall MB, Thilo KV (2012) Vestibular inputs to human motion-sensitive visual cortex. Cereb Cortex 22:1068-1077

8. Lee SU, Suh HI, Choi JY, Huh K, Kim HJ, Kim JS (2014) Epileptic nystagmus: a case report and systematic review. Epilepsy Behav Case Rep 2:156-160 